\title{
Contractor's Attitude towards Risk and Risk Management in Construction in Two Western Provinces of Vietnam
}

\author{
Van Tien Phan \\ Department of Civil Engineering \\ Vinh University \\ Vinh City, Vietnam \\ vantienkxd@vinhuni.edu.vn
}

\begin{abstract}
Risk management is an important task in construction management that helps the contractor to actively identify, evaluate, control, and minimize negative impacts of risks on the project, thereby ensuring its effectiveness. People involved in the construction industry need to be well - equipped with information and knowledge to manage risks adequately and systematically. The purpose of this research is to explore the attitude towards risk and risk management in construction projects of the Vietnamese construction industry, with emphasis on the perspective of contractors. The research data are collected through a questionnaire associated with in-depth semi-structured interviews. The results indicate that the perception of risk within the Vietnamese construction industry includes both threats and opportunities. The majority of professionals in the industry have a risk-neutral approach, contrary to previous research. The importance of implementing effective risk management is shared, in the planning and production phase while risk identification was perceived to be the most important out of the four core processes.
\end{abstract}

\section{Keywords-contractor; risk; risk management; construction}

\section{INTRODUCTION}

Risk management in construction is designed to plan, monitor, and control those measures needed to prevent exposure to risk. To do this, it is necessary to identify the hazard, assess the extent of the risk, provide measures to control the risk and manage any residual risks. The integration of an effective risk management is considered essential for the project's success. Construction projects are described as tremendously complex and uncertainty might arise from various sources. Risk management is therefore becoming an extensive component of the project management in civil engineering in a pursuit to efficiently deal with unexpected risks and uncertainty. However, the managing of the adverse effects of risk and uncertainty in construction projects is rated ineffective, resulting in delays and a failure to meet quality and cost targets [1]. The aim of applying an efficient risk management procedure is to facilitate risk neutral decisions, resulting in superior performance. In order to obtain more information about risk and uncertainty of the construction project, different methods needed to be applied systematically
[2]. Although the application of various such techniques will not remove all risks, it ensures that the risks are assessed and managed in a manner allowing the overall objectives of the project to be achieved [3].

Risk management in construction is identifying, analyzing, and taking steps to reduce or eliminate the exposures to loss faced by an organization or individual. The practice utilizes many tools and techniques, including insurance, to manage a wide variety of risks. This allows the project to be prepared for unavoidable issues with increased transparency [4]. This process is repeated continuously throughout the entire project life cycle due to the constant possibility of emerging risks. Risk and uncertainty must be identified, assessed and responded from the earliest possible phases in order to achieve an efficiently dealt with when they arise [3]. The benefits of the process are the clearer understanding of the specific risks associated with the project, supported decisions by detailed analysis and a built-up of historical data that can be used to assist future risk management procedures. However, many contractors have still not realized the importance of applying risk management techniques as an integral part of the delivery of a project [1]. Inefficient risk management has many causes, including the lack of formalized procedures, the discontinuity in different phases of the construction project, and the inadequate integration of knowledge management and interaction between processes and parties [1]. In place of the contractors, the responsibility to deal with risks is deciding if the risks should be reduced, avoided, transferred, or retained [6]. The contractor needs to understand the importance of risk and risk management capabilities to achieve effective risk implementation [7].

In this research, risk management in the Vietnamese construction industry has been investigated, with focus being given on the attitude of the contractors towards risk and risk management techniques. The contractors participating in the survey were selected from small and large companies. The research is limited to the Vietnamese construction organization in two main provinces in Vietnam, Vinh Long and Can Tho. 


\section{RESEARCH METHODOLOGY}

The research was carried out using a mixed method, in which both quantitative and qualitative data collection techniques and analytical procedures were used [8]. Therefore, this form of survey integrates two types of data and the core assumption of this approach is that a combination of qualitative and quantitative methods leads to a better understanding of the problem [10]. Mixed approach studies use multiple approaches in answering research questions, and are not restricted or limited [11]. Previous research includes thorough understanding of the field of study and formulating research questions. The next step involves preparing a set of semistructured interview questions and building a questionnaire based on the theoretical framework. These steps are needed in order to achieve the purpose of this study, which is to understand the perceptions, knowledge, and practical implementations of risk management process in constructions in Vietnam. The questionnaire was designed to identify attitudes, knowledge, and risk management application in the Vietnamese construction industry. A survey strategy is associated with inference methodology and tends to be used for exploratory and descriptive research. It allows potential gathering of large amounts of data from a large population [8]. The purpose of descriptive research is to obtain an accurate representation of the person or situation, thus describing the characteristics of the phenomenon under investigation. A questionnaire is one of the most commonly used data collection techniques in surveys. Each individual is provided with a questionnaire and is asked to answer the same set of questions, allowing a way to collect answers from a large sample before analysis [8]. A successful questionnaire should be short and simple [12]. Simplified questions should be conducted in a logical sequence that moves from easier to more difficult. The questions provided in the survey may be open-ended allowing unlimited answers, bidirectional in which the answer is limited to a pair of alternatives such as yes or no, rating questions, and finally multiple-choice questions in which the respondents are asked to choose the most suitable option.

The goal was to get an overall representation of the industry related to risk management. The questionnaire consisted of 29 questions divided into three parts. The first part was designed to collect background information and reveal respondents' perceptions and attitudes towards risk management. The purpose of the second part was to explore ways to manage and transfer knowledge in the respective companies, and the third part covered practical risk management and implementation methods in the industry. An invitation was emailed to 336 Vietnamese contractors a total of 43 responses were received, with a response rate of approximately $13 \%$. The average response rate for external surveys is around $10-15 \%$. About $70 \%$ of the respondents had more than 15 years of experience within the construction industry and the majority $(88 \%)$ where contractors, $24 \%$ where developers and 2,38\% where consultants. The size of the companies where equally represented, approximately $48 \%$ had more than 1000 employees while 52\% had less than 1000 employees.

\section{RESULTS}

The results of this study show the respondents' perception of risks and how they view risk management in terms of importance. The respondents covered a variety of occupations in Vietnamese construction industry, representing the overall picture of risk management perception and implementation, with their majority having more than 10 years of experience to enhance their credibly. Contractors were the $78 \%$, developers (clients) the $19 \%$, and consultants the $13 \%$ of the participants. Interviews were conducted only with contractors. An equal distribution among company sizes was attained in the data collection, as stated above. A difference of opinion related to the company size will merely be mentioned when a significant differentiation can be observed between them, otherwise an overall picture of the industry will be presented due to similar answers to the questions. The results indicate that the attitude among Vietnamese contractors regarding risk is a combination of both opportunity and threat. This contradicts the results presented by [5] where the construction industry is predominantly risk averse. The overwhelming majority of the respondents in both the questionnaire and the interviews described themselves as being risk-neutral rather than riskaverse or risk-seekers, which coincides with previous studies. Hence, their attitudes and perception of risk are in line with their risk approach profile as risk-neutral decision makers. One of the interviewees viewed risk as overall negative consequences depending on the type of risk, although he stated that an opportunity might be found when dealing with financial risks. However, the majority of respondents described risks as a mix of threat and opportunity since risks might lead to exploring other ways of managing hazardous situations which may be more prosperous.

\section{A. Questionnaire}

The related part of the questionnaire consisted of the following questions:

\section{1) How Do you Perceive Risk within the Construction Industry?}

The answers show that the majority of respondents' attitudes toward risk were a combination of threats and opportunities, as shown in Figure 1. Only two respondents perceived risk only as a threat, two more respondents realized that the risk was something positive, that is only an opportunity. However, about $90 \%$ (30 people) of the respondents perceived the risks in the construction industry as a combination of both positive and negative associations.

\section{2) What is your Attitude in Relation to Tisk?}

About 5\% of respondents feel they have a risk-seeking personality while $13 \%$ say they do not like risks. The majority, around $82 \%$, has a risk-neutral approach and can balance between avoiding and seeking risks. Therefore, a correlation between their cognitive traits and their attitudes is observable.

\section{3) Which Stage/Phase Do you Consider Most Important in Risk Management?}

Respondents varied quite a lot when asked at what stage they considered the implementation of risk management to be the most important. The reason for this is probably the 
professional diversity among respondents because developers and consultants probably value the completion phase more in relation to construction and site managers consider planning and production risks in higher priority. However, the findings indicate that the majority consider the planning stage as the most important stage to implement risk management. This is followed by production, then conceptual stage and finally by the completion and finishing stages, as shown in Figure 2.

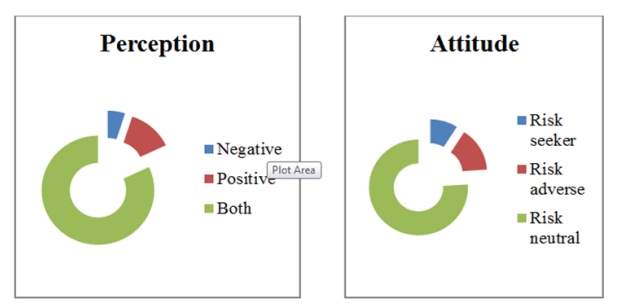

Fig. 1. Respondents risk perception (left) and respondent's attitude in relation to risk.

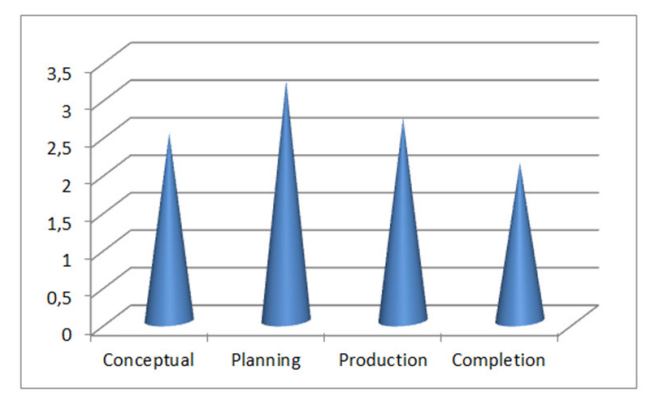

Fig. 2. Answers on "Which stage do you consider most important for Risk Management?".

\section{4) Which Risk Management Process is Most Important?}

Risk identification was perceived by the respondents as the most important risk management process as shown in Figure 3. Risk assessment, risk response, and risk monitoring phase are considered rather equally important with small variances in opinion.

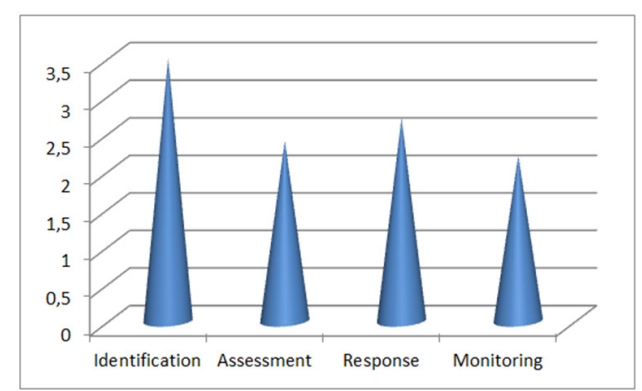

Fig. 3. Answer on "Which Risk Management process is most important?".

The questionnaire revealed that the respondents perceived risk management to be most important during the planning and production rather than the conceptual and completion phases. The result illustrates that every phase is considered highly important since the planning and production phase didn't exceed the other phases significantly. This outcome is probably caused by the fact that the participants came from various professions within the industry, in which different risks are considered. Furthermore, out of the four core processes in risk management, the respondents viewed risk identification to be the most important while assessment, whereas response and monitoring where rather equally significant. This parallels the claim by [7] that the identification process might be viewed as the most crucial step.

\section{B. Interviews}

The perception of risk management as the adoption of efficient processes of managing risks was shared among all the interviewees. Risk management is crucial in order to achieve project objectives. The projects in the construction industry are filled with risks and uncertainty, thus it is essential to have an effective risk management process in place. The concept described in the literature facilitates the ability to maximize opportunities and simultaneously reduce threats. However, no universal standard or method can be observed among the respondents in the interviews, with the implementation of risk management varying in practice. Nonetheless, four stages where considered as the core process within the construction industry even though there are many methodologies used for risk management [1]. The findings from the interviews revealed that even though the respondents didn't have previous knowledge regarding theoretical models and processes they still had analogous organizational processes. Hence, they were indirectly practicing risk management similar to the concepts described in the literature. The respondents described a general identification process in order to shed light on various risks followed by an assessment of the risks and a prioritization depending on impact and probability, which was determined by experience and discussion. This process is iterative and continuous throughout their projects, which is the essential information loop principal used when describing the use of an effective risk management implementation [2]. In terms of work environment risks, it was stated by one respondent that they made sure to manage a high impact risk scenario straightaway while low risks were allowed to be fixed during a longer time period. All respondents emphasized the importance of discovering risks as early as possible.

\section{CONCLUSIONS}

By preparing a set of semi-structured interview questions and by building a questionnaire based on the theoretical framework, the perceptions, knowledge, and practical implementations of risk management process in the construction industry in Vietnam have been investigated. The questionnaire was designed to identify attitudes, knowledge, and risk management application in the Vietnamese construction industry.

The contractors participating in the questionnaire were selected from small and large companies in Vinh Long and Can Tho provinces. The perception of risk within the Vietnamese construction industry includes awareness of threats and opportunities. The majority of the professionals in the industry have a risk neutral approach, a result that comes in contrast with the findings in [5]. The importance of implementing an effective risk management is shared, especially in the planning 
and production phases, while risk identification was perceived to be the most important of the four core processes.

\section{REFERENCES}

[1] N. J. Smith, T. Merna, and P. Jobling, Managing Risk: In Construction Projects, 2nd ed. Hoboken, NJ, USA: Wiley-Blackwell, 2009.

[2] G. M. Winch, Managing Construction Projects, 2nd Edition. Chichester; Ames, Iowa: Wiley-Blackwell, 2009.

[3] K. Potts, Construction Cost Management: Learning from Case Studies. London, UK: Routledge, 2014.

[4] M. Schieg, "Risk management in construction project management," Journal of Business Economics and Management, vol. 7, no. 2, pp. 7783, Jan. 2006, https://doi.org/10.1080/16111699.2006.9636126.

[5] A. S. Akintoye and M. J. MacLeod, "Risk analysis and management in construction," International Journal of Project Management, vol. 15, no. 1, pp. 31-38, Feb. 1997, https://doi.org/10.1016/S0263-7863(96)00035$\mathrm{X}$.

[6] J. Liu, B. Li, B. Lin, and V. Nguyen, "Key issues and challenges of risk management and insurance in China's construction industry: An empirical study," Industrial Management \& Data Systems, vol. 107, no. 3, pp. 382-396, Jan. 2007, https://doi.org/10.1108/02635570710734280.

[7] M. N. K. Saunders, A. Thornhill, and P. Lewis, Research Methods for Business Students, 5th Edition. New York, NY, USA: Pearson, 2009.

[8] A. F. Serpella, X. Ferrada, R. Howard, and L. Rubio, "Risk Management in Construction Projects: A Knowledge-based Approach," Procedia Social and Behavioral Sciences, vol. 119, pp. 653-662, Mar. 2014, https://doi.org/10.1016/j.sbspro.2014.03.073.

[9] R. B. Johnson and A. J. Onwuegbuzie, "Mixed Methods Research: A Research Paradigm Whose Time Has Come:," Educational Researcher, vol. 33, no. 7, 2004, https://doi.org/10.3102/0013189X033007014.

[10] P. T. Nguyen and P. C. Nguyen, "Risk Management in Engineering and Construction: A Case Study in Design-Build Projects in Vietnam," Engineering, Technology \& Applied Science Research, vol. 10, no. 1, pp. 5237-5241, Feb. 2020, https://doi.org/10.48084/etasr.3286.

[11] M. S. Shahbaz, A. G. Kazi, B. Othman, M. Javaid, K. Hussain, and R. Z R. M. Rasi, "Identification, Assessment and Mitigation of Environment Side Risks for Malaysian Manufacturing," Engineering, Technology \& Applied Science Research, vol. 9, no. 1, pp. 3852-3858, Feb. 2019, https://doi.org/10.48084/etasr.2529.

[12] A. Chenarani and E. A. Druzhinin, "A Quantitative Measure For Evaluating Project Uncertainty Under Variation And Risk Effects," Engineering, Technology \& Applied Science Research, vol. 7, no. 5, pp 2083-2088, Oct. 2017, https://doi.org/10.48084/etasr.1530. 